\title{
Expressões e sentidos do lúpus eritematoso sistêmico (LES)
}

\author{
Adriana Dias Araújo \\ Secretaria Municipal de Assistência Social - Natal, RN \\ Martha Azucena Traverso-Yépez. \\ Universidade Federal do Rio Grande do Norte
}

\begin{abstract}
Resumo
O lúpus eritematoso sistêmico (LES) é uma doença crônica e auto-imune que gera diversos quadros clínicos que se tornam uma ameaça à vida da pessoa. Sua etiologia aponta para a combinação de fatores genéticos, hormonais e ambientais, e sua incidência recai principalmente em mulheres. Acredita-se que os sentidos atribuídos ao processo de adoecer influenciam no tratamento do LES e na forma de lidar com as dificuldades desse processo. Objetivando aprofundar os processos de significação e geração de sentidos relacionados à experiência de LES, foram entrevistadas oito mulheres portadoras da doença. A análise das narrativas evidencia que não é só o LES que tem inúmeras maneiras de se apresentar, mas a experiência da doença é subjetiva e dinâmica, tendo diversas formas de significação conforme as condições advindas do processo de adoecer e suas implicações. Ratifica-se, assim, a necessidade de uma abordagem interdisciplinar que abarque essa complexidade, considerando a dimensão biopsicossocial envolvida no processo.
\end{abstract}

Palavras-chave: doença crônica; lúpus eritematoso sistêmico; produção de sentidos

\begin{abstract}
Expressions and sense making process about Systemic Lupus Erythematous (SLE). Systemic Lupus Erythematosus (SLE) is a chronic and auto-immune disease which causes different clinical syndromes that can put in risk the person's life. Its etiology indicates the combination of genetic, hormonal and environmental factors, presenting a higher incidence among women. It is believed that meanings attributed to the illness process influence its treatment, as well as the person's capacity to cope with the difficulties implicit in the illness process. Aiming a study in depth of meanings and sense making process related to the experience of SLE, eight women affected by the disease were interviewed. The analysis of their narratives shows not only the different symptoms and complex clinic evidences related to SLE, but also the diverse subjective and dynamic ways the illness is experienced. This ratifies the necessity of an interdisciplinary approach to embrace the SLE complexity.
\end{abstract}

Keywords: chronic disease; Systemic Lupus Erythematosus; sense making processes

$\mathrm{O}$ lúpus eritematoso sistêmico (LES) é uma doença crônica e auto-imune que pode atingir vários órgãos e sistemas do corpo, gerando diversos quadros clínicos que podem ser fonte de incapacidade física e profundo sofrimento psicológico, bem como uma ameaça à vida da pessoa (Dobkin et al, 2001; Moreira \& Mello Filho, 1992).

Reconhece-se que esse tipo de doença crônica tem uma dimensão psicossomática prevalente, sendo importante considerar o estresse e o sofrimento psicossocial no seu desencadeamento, evolução, agravamento e possível controle (Moreira \& Mello Filho, 1992). Esse quadro mostra a necessidade de uma intervenção interdisciplinar no atendimento às pessoas portadoras de LES, bem como considerar a forma peculiar da doença se expressar na vida de cada pessoa, já que os aspectos psicossociais envolvidos contribuem para a complexidade do desenvolvimento e exacerbação dos sintomas (Radley, 1999).
O presente artigo é um recorte de uma pesquisa maior que objetivou aprofundar na análise da experiência de oito mulheres portadoras de LES, atentando para os processos de significação e produção de sentidos ao lidar com as implicações da doença.

Embora nosso foco seja a dimensão psicossocial, um conhecimento mínimo da complexidade biológica da doença é necessário para possibilitar esse diálogo interdisciplinar. Assim, na primeira parte do artigo faz-se um breve esboço sobre a doença e suas implicações, para depois enfatizar nossa perspectiva de trabalho na interface da psicologia social e os processos saúdedoença. A seguir apresentam-se as estratégias da pesquisa e a análise das narrativas sobre a experiência da doença.

Acredita-se que considerar os processos de subjetivação da pessoa portadora na interação com o contexto do qual ela faz parte pode influenciar positivamente no tratamento e na forma de lidar com as dificuldades implícitas nesse processo do adoecer. 
Pode, ainda, contribuir para que profissionais e pessoas afetadas estejam mais cientes dessa complexidade.

\section{Conhecendo o lúpus eritematoso sistêmico: implica- ções e tratamento}

Embora seja um artigo dirigido principalmente a psicólogos, considerou-se necessário fazer uma revisão sintética da complexidade implícita na própria doença. Os primeiros estudos acerca da doença aconteceram a partir da década de 50, quando o médico Pierre Cazenave constatou em várias pessoas lesões avermelhadas na face que cobriam o nariz e as bochechas, causando "feridinhas". Comparou-as às mordidas de lobo, dando à doença o nome de lúpus eritematoso (lúpus = lobo, eritematoso $=$ vermelho) (Zerbini \& Fidelix, 1989).

Estudos epidemiológicos apontam que o LES é mais freqüente entre mulheres, numa proporção de nove mulheres para cada homem, sendo sua incidência maior entre os 15 e 45 anos (Sato, 1999; Sato et al, 2002; Zerbini \& Fidelix, 1989). No Brasil, de acordo com Sato (1999), não há estudos epidemiológicos mostrando a incidência de LES na população'; enquanto que nos Estados Unidos estima-se que uma pessoa em cada 2000 apresenta a doença (Zerbini \& Fidelix, 1989). Contudo, na cidade de Natal, em estudo realizado por Villar e Sato (2001), a incidência é de 8,7/100.000/ano, o que parece ser maior que em outras partes do mundo, em virtude da permanente presença de luz solar com alto índice de raios ultravioleta.

Pesquisadores acreditam na possibilidade do LES ser herdado, contudo, a constatação da doença nos pais ou avós não quer dizer que a pessoa terá a doença; entretanto, há uma maior propensão em manifestá-la. Sua etiologia aponta, assim, para a combinação de fatores genéticos, hormonais e ambientais, já que a industrialização e alterações nos hábitos de vida parecem contribuir para elevar os índices do LES. A junção desses fatores em pessoas geneticamente predispostas pode gerar um desequilíbrio no sistema imunológico, favorecendo o surgimento do lúpus (Sato, 1999; Sato et al, 2002; Zerbini \& Fidelix, 1989).

O LES é uma doença inflamatória, auto-imune, que pode atingir múltiplas partes do corpo, principalmente a pele, as juntas, o sangue e os rins, e pode causar sérios problemas ao longo da vida. O sistema imunológico produz anticorpos para proteger o organismo de antígenos (corpos estranhos). Havendo uma desorganização imunológica, o sistema defensivo deixa de distinguir entre os antígenos e as células e tecidos do próprio corpo, direcionando anticorpos contra si mesmo, os quais reagem formando complexos imunológicos que crescem nos tecidos e podem causar inflamação, lesões e dores (Zerbini \& Fidelix, 1989).

Zerbini e Fidelix (1989) sistematizam os principais sintomas da doença em ordem de incidência: artrite, febre, problemas na pele, tais como vermelhidão em "asa de borboleta", fotossensibilidade, queda de cabelo, fenômeno de Raynaud (coloração de mãos e pés), feridinhas no nariz e na boca, bem como cansaço, perda de peso, problemas renais, problemas pulmonares, problemas cardíacos, aumento de gânglios, depressão e, até, complicações neurológicas e psicóticas, que fazem parte de outras doenças. Essa combinação de sintomas diferentes em cada pessoa torna difícil o diagnóstico de lúpus. Contudo, as novas técnicas de laboratório e o maior conhecimento e habilidade dos médicos para identificar a doença tendem a minimizar as dificuldades do diagnóstico.

A pessoa terá o diagnóstico de LES caso apresente pelo menos quatro destes sintomas, os quais podem ocorrer simultaneamente ou separadamente. É um diagnóstico complexo feito através da avaliação clínica, junto com o hemograma, análise da urina e exames que avaliam o sistema imunológico.

As dores nas juntas e nos músculos ocorrem em $90 \%$ dos casos. Os músculos podem ser gravemente danificados pela doença, podendo resultar em fraqueza e perda da resistência, caso não seja dado um tratamento adequado no início do problema (Stevens, 2001). A inflamação dos rins também é freqüente e ocorre em cerca de $50 \%$ dos casos. Além disso, os medicamentos utilizados no controle do lúpus podem gerar problemas renais que se confundem com a nefrite lúpica.

De acordo com Chartash (2001), o lúpus pode atingir todas as partes do coração, sendo a inflamação no pericárdio a doença mais comum, que pode, ou não, gerar dores no peito. Entretanto, a arteriosclerose é a causa mais freqüente de problemas coronários. Tais prejuízos no coração podem ser oriundos da inflamação causada pela doença em atividade ou, também, pelo uso de medicamentos. O lúpus pode, ainda, causar anemia, gerando cansaço, sonolência e indisposição; se a anemia for aguda, poderá causar falta de ar e palpitações, mas tende a regredir quando o LES está inativo.

O envolvimento do sistema nervoso, como assinala Hanly (1991), ocorre em cerca de 75\% das pessoas, o que gera convulsões, perda de sensibilidade, disfunção de habilidades motoras, depressão, psicose e síndrome orgânica do cérebro. Esta síndrome se caracteriza por uma deterioração abrupta ou gradual da memória, da orientação e da concentração, as quais não são necessariamente permanentes, ocorrendo em algum momento do curso da doença em até $50 \%$ das pessoas. Mesmo assim, as pessoas podem manter um estilo de vida relativamente normal.

Zerbini e Fidelix (1989) apontam a psicose e a depressão como as complicações neuropsiquiátricas mais freqüentes. O fato das pessoas serem portadoras de doença crônica tende a criar uma noção distorcida de que essas pessoas têm razões para se sentirem deprimidas em virtude da doença, o que impede a realização de um diagnóstico precoce. Grande parte das crises depressivas em pessoas portadoras de LES tem curta duração, desaparecendo em alguns meses, mas devem ser tratadas com o mesmo empenho e persistência com que se trata qualquer outra expressão da crise lúpica.

O tratamento do LES deve ser personalizado e dependerá, além da gravidade, dos órgãos ou sistemas afetados. No caso de envolvimento multissistêmico, o tratamento deverá ser orientado para a queixa de maior gravidade (Sato et al, 2002). A medicação mais potente para tratar o LES é o corticóide, no entanto, este também provoca diversos efeitos colaterais (enfraquecimento dos ossos, diabetes, catarata, inchaço do rosto e do corpo). Em alguns casos, os imunossupressores também são usados para regular a ação do sistema imunológico que se encontra desequilibrado (Zerbini \& Fidelix, 1989). 
Com relação à gravidez, as pesquisas de Lockshin (2001) mostram que $50 \%$ de todas as gestações em mulheres com lúpus são completamente normais, $25 \%$ geram bebês prematuros e $25 \%$ correspondem à perda do feto, por aborto espontâneo ou morte do bebê. A mortalidade perinatal será essencialmente mais elevada quando o LES é severo e mal controlado. Acredita-se que a doença pode se exacerbar no período próximo ao momento do parto e até oito semanas após. Contudo, o acompanhamento sistemático pode minimizar a exacerbação da doença (Sato, 1999; Zerbini \& Fidelix, 1989).

O melhor momento para a portadora de LES engravidar é quando a doença está inativa, mas todas as gestações devem ser consideradas de alto risco devido à severidade da patologia e à necessidade do acompanhamento medicamentoso (Lockshin, 2001). Contudo, ter a doença não impede que a mulher engravide e gere bebês saudáveis, embora toda intervenção durante a gestação deva ocorrer sob o acompanhamento conjunto entre o reumatologista e o ginecologista. Aquelas que não desejam engravidar devem procurar um médico para escolher o método contraceptivo, lembrando que o estrógeno contido nas pílulas anticoncepcionais pode ativar a doença.

Diante dessa complexidade, algumas orientações são essenciais para as pessoas portadoras de LES: (a) bom nível de informação da doença e suas implicações; (b) evitar o sol e as lâmpadas em função da radiação ultravioleta; (c) contar com apoio psicológico; (d) manter uma disciplina mínima de atividade física conforme as limitações de cada pessoa; (e) adotar uma dieta balanceada, evitando os excessos de sal, carboidratos e lipídios; (f) evitar o tabagismo; (g) no caso das mulheres, é recomendável se abster do uso de anticoncepcionais em função do estrógeno, apontado como um dos desencadeadores da doença; (h) evitar infecções; e (i) saber diferenciar os sintomas que podem ser causados por outros problemas de saúde (Krauthamer, Coelho, \& Sato, 1999; Sato et al, 2002).

Fica em evidência que a experiência do LES não é coisa fácil, demandando cuidados e mudanças no próprio estilo de vida, que são dependentes de como a pessoa significa o processo de adoecer.

\section{Significando e gerando sentidos acerca do adoecer}

A atenção aos processos de significação e geração de sentidos faz parte de uma concepção do conhecimento e dos processos psicossociais estreitamente ligados à ação. $\mathrm{O}$ conhecimento deixa de ser um estado mental interno e passa a ser considerado como parte da ação, um modo peculiar de nos relacionar com as situações existenciais, significando e nos posicionando na dinâmica dos processos de intersubjetivação. É uma abordagem teórico-metodológica embasada no referencial do construcionismo social, que reconhece a centralidade da linguagem para definir os termos através dos quais compreendemos e lidamos com os fenômenos à nossa volta (Spink \& Gimenes, 1994).

Esse processo de significar a nós mesmos e ao mundo, também permite que os sentidos sobre a doença sejam permanentemente modificados. De acordo com Grandesso (2000): “a rede de significados do indivíduo pode ser reconstruída em razão do caráter performativo da linguagem" (p. 194). Deve ficar claro que a reconstrução de significado, segundo a autora, quer dizer a mudança de sentidos a partir das novas narrativas que ordenam tanto a experiência presente como, também, a passada, vislumbrando ainda as possibilidades futuras.

No caso de uma doença crônica, percebe-se que cada pessoa processa os diversos significados a partir das relações sociais no contexto no qual está inserida, na sua história de vida e nas suas experiências. Destaca-se que, ainda que a doença seja a mesma, cada pessoa constrói sentidos diferenciados. Uma pessoa pode inferir que a partir da doença sua vida tornou-se sem rumo e direção, enquanto outra a percebe como algo que lhe deu um senso de ordem e propósito (Remen, 1993). Igualmente, os sentidos atribuídos pela pessoa são dinâmicos, sendo construídos e permanentemente processados através das peculiaridades da doença e da rede de significados (de médicos, outros portadores de lúpus, vizinhos, amigos, familiares e outros) que fazem parte do seu cotidiano. Assim, os sentidos construídos no momento do diagnóstico ou em que a doença está em atividade são distintos daquele em que a pessoa convive com a patologia, mas com pouca ou nenhuma reincidência.

Observa-se, portanto, que é importante conhecer os sentidos dados pelos(as) portadores(as) de lúpus, pois isso constitui o primeiro passo para intervenções que permitam uma abordagem mais criteriosa da doença. Na exploração da relação da pessoa com sua própria doença reside uma das contribuições da psicologia na interface com a saúde, já que permite trabalhar com o que Campos (1992) denomina "a vontade de cura" (p. 45). Ou seja, trata-se de identificar o potencial de recursos psicossociais capazes de ajudar a pessoa a lidar melhor com esse sofrimento.

\section{Estratégia de pesquisa}

A fim de conhecer e compreender os sentidos atribuídos acerca do adoecer, a estratégia utilizada foi a entrevista em profundidade, considerada como um processo de comunicação que ocorre entre dois atores sociais (pesquisador e participante). A entrevista viabiliza a elaboração de narrativas e a identificação e compreensão dos sentidos produzidos sobre o adoecer. Acredita-se que, nessa relação dialógica, a maior beneficiada deve ser a própria participante, ao ter espaço para organizar narrativamente a experiência da doença (Bruner, 1997; Grandesso, 2000; Murray, 1999).

O Hospital Universitário da Universidade Federal do Rio Grande do Norte foi a instituição escolhida para a realização da coleta de dados, pois é referência no estado no diagnóstico e tratamento do LES. Uma vez obtida a autorização para o desenvolvimento da pesquisa no hospital, o projeto foi submetido e aprovado pelo Comitê de Ética em Pesquisa da UFRN, conforme os critérios estabelecidos pela Resolução № 196/96, do Conselho Nacional de Saúde-CNS.

O critério para seleção dos participantes foi ser portador de LES, estar em atendimento ambulatorial, ser do sexo feminino (por ser a maior incidência), residir na cidade de Natal e ter disposição para participar da pesquisa. Assim, foram entrevistadas oito participantes que assinaram o Termo 
de Consentimento Informado como requerido pelo Comitê de Ética.

As entrevistas ocorreram individualmente e para efeito do presente artigo será feito um recorte da pesquisa mais ampla para considerar, além dos dados sócio-demográficos, os processos de geração de sentidos sobre esse adoecer. Todas as entrevistas foram gravadas em áudio, para posterior transcrição e análise, garantido o absoluto sigilo das informações.

O contato inicial com as participantes foi feito pessoalmente, na sala de espera do ambulatório do hospital, porém, decidiu-se que as entrevistas seriam realizadas em outro dia e em outro local, para garantir a privacidade e o sigilo que requer a situação. Embora se tenha combinado que a coleta seria feita no hospital, duas entrevistas foram realizadas na casa das participantes por estas terem limitações para se locomover até o hospital.

De forma geral, as participantes mostraram-se mais receptivas durante a entrevista do que no primeiro contato ocorrido na sala de espera. Isso foi constatado pela motivação expressada no transcorrer do encontro e a boa disposição para responder e participar, apesar de uma delas estar com a doença em atividade e sentindo dores durante a entrevista.

\section{Conhecendo as participantes}

Com a finalidade de contextualizar e contar quem são as mulheres que compõem o presente estudo, o roteiro de entrevista contemplou dados como: idade, estado civil, escolaridade, religião, profissão e/ou situação ocupacional, renda familiar; bem como, informações sobre maternidade. A fim de respeitar a privacidade das participantes, cada uma é identificada aqui apenas com uma letra do alfabeto em ordem seqüencial. A Tabela 1 apresenta o perfil das oito participantes.

A renda per capita de seis participantes era inferior ao salário mínimo ${ }^{2}$; cinco das participantes tinham uma renda per capita entre 80 a 180 reais; uma entre 181 a 281; e duas entre 282 a 382 reais. Essa renda tende a ser mais comprometida, considerando os gastos oriundos do tratamento medicamentoso para manter a doença sob controle. A situação profissional antes e após a doença, bem como a ocupação atual é apresentada na Tabela 2.

Tabela 1

Perfil das participantes

\begin{tabular}{cclll}
\hline Participante & $\begin{array}{c}\text { Idade } \\
\text { (anos) }\end{array}$ & Estado civil & \multicolumn{1}{c}{ Escolaridade } & \multicolumn{1}{c}{ Religião } \\
\hline A & 22 & Solteira & $1^{\underline{0}}$ ano do $2^{\underline{0}}$ grau & Católica \\
B & 18 & Solteira & $3^{\underline{0}}$ ano do $2^{\underline{0}}$ grau & Evangélica \\
C & 42 & Solteira & $2^{\underline{0}}$ grau completo & Católica \\
D & 39 & Solteira & $4^{\underline{a}}$ série do $1^{\underline{0}}$ grau & Católica \\
E & 39 & Solteira & $2^{\underline{a}}$ série do $1^{\underline{0}}$ grau & Católica/evangélica \\
F & 46 & Separada & $2^{\underline{0}}$ grau completo & Católica \\
G & 21 & Solteira & $2^{\underline{o}}$ grau completo & Católica \\
H & 44 & Casada & $3^{\text {o }}$ grau completo & Católica \\
\hline
\end{tabular}

Tabela 2

Situação profissional e ocupacional das participantes

\begin{tabular}{llll}
\hline$n$ & Profissão antes da doença & \multicolumn{1}{c}{ Após a doença } & \multicolumn{1}{c}{ Ocupações atuais } \\
\hline 1 & Operadora de caixa & Pensionista & Nenhuma \\
1 & Auxiliar de serviços gerais & "Encostada pela perícia" & Nenhuma \\
1 & Auxiliar de costura & Aposentada por invalidez & Nenhuma \\
1 & Costureira-operária & Aposentada por invalidez & Nenhuma \\
1 & Professora & Aposentada por invalidez & Escritora, relações públicas, \\
& & & vendedora autônoma e voluntária \\
3 & Estudante & Estudante & Estudante \\
\hline
\end{tabular}

Observa-se que a doença impediu que cinco participantes continuassem seus trabalhos regulares. Porém, para algumas delas permitiu a realização de atividades autônomas (trabalho manual, escritora e vendedora) que são mais flexíveis às regras estabelecidas pelo Ministério do Trabalho que determina uma jornada em torno de 6 a 8 horas diárias. Uma carga horária fixa torna-se, na maioria dos casos, impraticável conforme os sintomas apresentados quando a doença está ativa. A maioria declarou ficar impossibilitada de se locomover, o que exigiu a suspensão de toda atividade.

\section{Significando e gerando sentidos acerca da experiência do LES}

A análise das narrativas objetivando a produção de sentidos organizou-se a partir dos seguintes eixos temáticos: (a) como a doença se expressa; (b) observações sobre o que prejudica e o que ajuda no controle da doença; (c) a convivência com o LES; (d) mudanças e limitações decorrentes do lúpus eritematoso sistêmico e (e) a doença e os projetos de vida. 


\section{Como a doença se expressa}

A diversidade de sintomas manifestados pelas participantes como: inchaço nas articulações, dor, problemas de pele, dificuldade de locomoção, depressão, febre, problema respiratório, problemas de visão, queda de cabelo, feridas, problemas de circulação, perda de peso, inflamação nos rins, problemas no coração, pressão alta, ascite (acúmulo de líquido na cavidade abdominal), unhas pretas, sangramento na gengiva, anemia e nódulo, revelam a variedade dos sintomas do LES e a complexidade do quadro clínico. Isso evidencia o porquê dessa patologia ser confundida com outras doenças e as dificuldades para chegar ao diagnóstico.

A maioria das participantes destaca a presença de sintomas simultâneos, sendo o inchaço e dores em diversas partes do corpo, as principais queixas. Constata-se, igualmente, que a artrite afeta a todas as participantes, estando de acordo com Zerbini e Fidelix (1989), que a apontam como um dos sintomas essenciais do lúpus. A inflamação das juntas pode ser tão severa, que cinco mulheres afirmam ter perdido a capacidade de locomoção nos momentos de crise.

Os problemas na pele também são referidos por todas as participantes, podendo atingir não só o aspecto físico, como também o psicossocial, pois afetam a imagem corporal no momento em que os sintomas estão se manifestando e/ou ao deixarem algumas cicatrizes (Meinão, Assis, \& Sato, 1999; Zerbini \& Fidelix, 1989). Isso pode causar constrangimento à pessoa portadora diante daqueles que ficam curiosos e até questionam o tipo de doença e se esta é contagiosa.

Considerando que o sistema nervoso também é atingido pelo LES, segundo as participantes, os sintomas de depressão foram evidentes, principalmente na fase inicial da doença. No momento da entrevista, as participantes " $D$ " e "E" apresentaram alguns sintomas de ansiedade e depressão. Contudo, torna-se difícil distinguir se fazia parte da doença ou era em decorrência do impacto emocional gerado pela situação existencial vivenciada pelas mesmas (Shapiro, 2001).

Além da diversificada sintomatologia apresentada pelas participantes, considerou-se relevante conhecer se elas identificam situações específicas em que os sintomas retornam. As participantes "C" e "G" foram categóricas ao afirmar que desconhecem a situação em que os sintomas voltam. Contudo, a justificativa de "C" reside no fato dos sintomas não retornarem com a mesma severidade do início da doença. Enquanto "G" explica que desde quando obteve o diagnóstico (há três anos) a doença encontra-se inativa.

Observa-se ainda a dificuldade em identificar situações específicas associadas ao aparecimento dos sintomas, quando a doença parece não dar trégua. Pelo fato da doença ter avançado em virtude do excesso de trabalho e pela idade, "F" considera que tem dificuldades em manter a doença sob controle e depende de altas doses do medicamento. Contudo, a volta dos sintomas é inevitável devido à sua evolução. Apesar disso, ela continua se mostrando ativa e, quando possível, fazendo trabalhos manuais para aumentar a sua renda. "F", de fato, expressa querer maximizar o que ainda pode controlar em relação à doença. Assim, apesar de adorar ir à praia, agora evita, por causa da exposição solar. Além disso, como reconhece que cansa rapidamente quando está na rua, sai apenas quando é imprescindível.

"B" também aponta que os sintomas reaparecem automaticamente quando a medicação é suspensa por ordem médica, evidenciando a dependência permanente do medicamento pela maioria das entrevistadas. A participante " $\mathrm{H}$ ", igualmente, refere-se à exposição solar como propiciador da reincidência dos sintomas; porém, enfatiza que diante de algum problema eles também reaparecem. Durante a entrevista, de forma recorrente fala sobre a crise do seu casamento e o quanto esse sofrimento conduz ao retorno dos sintomas.

Aspectos emocionais são também destacados como causadores da volta dos sintomas. Para "D", os sintomas voltam quando sente raiva, enquanto para "E" voltam diante dos problemas familiares. No entanto, "A" atribui o retorno dos sintomas a baixos níveis de temperatura. Embora alguns dos aspectos apontados como favorecedores do retorno dos sintomas possam ser controlados (evitar o sol, por exemplo), o estresse e os aspectos emocionais fogem do controle, porque ocorrem na dinâmica interacional com o mundo ao redor, nem sempre favorável ao bem estar das pessoas envolvidas. Isso revela a necessidade de uma escuta terapêutica para viabilizar formas de amenizar esse tipo de sofrimento.

Percebe-se que todas as participantes que já tiveram a doença ativa por mais de uma vez identificam a situação em que ocorre a volta dos sintomas; contudo, isso não garante o controle da mesma, porque os fatores emocionais, o estresse e a própria doença são marcados pela imprevisibilidade.

Com relação à maternidade, como a literatura aponta (Lockshin, 2001; Zerbini \& Fidelix, 1989), observa-se que ser portadora de LES não impede a possibilidade de ter filhos. Assim, três das oito entrevistadas engravidaram, uma delas quatro vezes. Contudo, deve-se destacar que, durante a época da gestação, nenhuma delas tinha sintomas ou o diagnóstico. De qualquer forma, no caso de "H", apesar de a doença ter surgido há sete anos e os dois abortos que sofrera terem acontecido muito tempo antes, ela acredita que o fato de não conseguir gerar uma criança está relacionado à sua patologia.

\section{Observações sobre o que prejudica e o que ajuda no controle da doença}

Para manter sob um relativo controle uma doença crônica não basta saber quais são as orientações que devem ser seguidas. É preciso também que a pessoa tenha in-corporado o que pode estar ajudando-a ou prejudicando-a nesse processo de adoecer. Nesse sentido, algumas participantes, quando questionadas sobre os aspectos que sentiam como prejudiciais à saúde, repetiram de forma quase mecânica: "não seguir as recomendações médicas, fazer extravagância, como ir à praia, pro sol, comer comida carregada" (A). Contudo, a participante "B", além de expressar que não tomar os remédios propicia o surgimento dos sintomas, aproveita para revelar a sua preocupação acerca da possibilidade de que o pai, em algum momento, não tenha condições econômicas para adquirir os medicamentos de que tanto precisa.

Igualmente, como nas situações em que ocorre o retorno dos sintomas, foram citados aspectos emocionais e a falta de apoio 
daqueles que as cercam. Assim, "C", "E", "G" e "H" manifestam como é prejudicial ter raiva, ter conflitos com os familiares e não ter o apoio destes. A participante "F" disse não fazer nada que prejudique o controle da sua doença, ao afirmar que segue todas as orientações médicas, tomando a medicação e fazendo a dieta, embora, às vezes, burle esta. Ainda que algumas participantes mencionem os efeitos colaterais provenientes da medicação, um aspecto interessante foi a participante " $D$ " ter sido a única a afirmar que é justamente a medicação que lhe traz prejuízo: "Que esse remédio pode curar, pode controlar o lúpus, mas eu sei que ele tá me prejudicando em outras coisas, pode ser uma gastrite, pode ser... qualquer coisa que já tenha aqui em mim".

Questionadas a respeito do que ajuda no relativo controle do LES, em contrapartida, ao que foi explicitado por " $D$ ", as participantes "B", "E" e "F" referem ser a medicação o elemento que mais ajuda a manter a doença inativa. Por outro lado, as participantes "A", "C", "D", "G" e "H" destacaram vários outros aspectos que também auxiliam no controle da doença, tais como: ter uma boa alimentação, ter acompanhamento médico, evitar o sol, não ter contrariedade, ter vontade de viver, distrair-se, caminhar e ter controle emocional.

Poder-se-ia pensar que há uma relação entre o que prejudica e o que ajuda no controle do LES. Isto é, se a medicação é o aspecto fundamental que ajuda no controle, a falta desta também seria o principal fator que prejudica. Contudo, percebe-se que nem todas as participantes fazem essa relação quando indicam os fatores emocionais como principais contribuintes para o descontrole da doença. Talvez isso se justifique pelo fato de a medicação ser um controle mais fácil de ser efetivado por elas; enquanto os aspectos emocionais são mais difíceis de serem evitados, pois não dependem somente delas e, sim, de todo um contexto familiar e social que propicia a ocorrência desses episódios estressantes.

\section{A convivência com o LES}

Os processos de significação e produção de sentidos, além de perpassarem a experiência dos sintomas, estão presentes também nas formas como as entrevistadas declararam vivenciar o LES, desde o surgimento dos primeiros sintomas, passando pelo processo de diagnóstico, até o momento atual. Como aponta a literatura, o diagnóstico da doença é difícil e o tempo, desde o aparecimento dos sintomas iniciais até o diagnóstico, pode se prolongar e ser marcado por grandes incertezas (Edelmann, 2000; Radley, 1994).

Observando o tempo de diagnóstico das participantes (ver Tabela 3), pode-se constatar que todas tiveram o surgimento da doença em período fértil (entre 17 e 39 anos), coincidindo com a faixa etária apontada na literatura (Sato, 1999; Zerbini \& Fidelix, 1989).

Tabela 3

Tempo de investigação, idade no diagnóstico e tempo de diagnóstico

\begin{tabular}{llllll}
\hline $\begin{array}{c}\text { Tempo de } \\
\text { investigação } \\
\text { diagnóstica }\end{array}$ & $n$ & $\begin{array}{c}\text { Idade no } \\
\text { diagnóstico }\end{array}$ & $n$ & $\begin{array}{c}\text { Tempo de } \\
\text { diagnóstico }\end{array}$ & $n$ \\
\hline 2 a 4 meses & 3 & 17 a 19 anos & 3 & 1 a 3 anos & 4 \\
5 a 7 meses & 2 & 26 anos & 2 & 7 anos & 2 \\
8 a 12 meses & 3 & 37 a 39 anos & 3 & 13 a 16 anos & 2 \\
\hline
\end{tabular}

Salienta-se, ainda, que enquanto quatro entrevistadas têm o diagnóstico de LES entre 01 e 03 anos, a outra metade das mulheres já o tem por um tempo igual ou superior a sete anos. Todavia, esse maior tempo de convivência com a doença parece não contribuir significativamente para a forma de perceber a sua enfermidade na atualidade. De fato, há outros fatores que influenciam essa experiência, tais como a reincidência e a gravidade dos sintomas, o apoio de familiares, a própria personalidade, a estrutura familiar (ter ou não filhos), a idade e os projetos de vida.

Praticamente todas as entrevistadas coincidem em relatar momentos de muito sofrimento físico e psíquico, já que manifestavam vários sintomas sem saber a razão destes. Todas falam de "muita dor e sofrimento", "tudo quanto era junta inchava", "levou um bocado de tempo para descobrir que era lúpus", "a gente já tava pensando que era uma coisa mais séria".

Com relação à reação ao diagnóstico, a maioria das mulheres declarou ter sentido dificuldade em recebê-lo. Assim, o diagnóstico foi tanto uma definição da patologia, como um momento em que a vida pode sofrer mudanças significativas conforme as especificidades da doença e dos sintomas experimentados, bem como, a necessidade de controlar e/ou minimizar a reincidência destes. Ademais, fica em evidência que as pessoas reagem de formas diferentes diante de eventos que podem parecer iguais, dependendo em muito da história de vida de cada uma, assim como do momento e das circunstâncias que elas estão vivendo (Edelmann, 2000; Radley, 1994; Remen, 1993).

A maioria das participantes expressou um sentimento de choque, centrado na constatação da doença não ter cura. Evidenciam-se nos depoimentos inquietações de todo tipo, oriundas da insegurança acerca de como será a vida, uma vez que o prognóstico é incerto e inevitavelmente exigirá mudanças, nem sempre fáceis ou viáveis, no estilo de vida (Edelmann, 2000; Radley, 1994).

Contudo, diante do sofrimento durante a fase dos primeiros sintomas, em alguns casos o diagnóstico tornou-se, também, uma forma de alívio. Assim para "F", o fato de saber que não era câncer se contrapôs ao possível mal-estar do diagnóstico. Está implícita a idéia, ainda muito presente no imaginário social, de que o câncer conduz necessariamente à condição de finitude (Spink \& Gimenes, 1994).

Observa-se nos discursos que, sendo os sintomas tão fortes, é bastante comum pensar em outras doenças incuráveis, até mesmo AIDS, como fora o caso de "H" e de "G". "G" relata que sofreu muito quando, no bairro, espalharam que ela tinha AIDS. Tal associação entre o LES e outras doenças crônicas é justificada pela gravidade e semelhança da sintomatologia.

Outro sentimento que está presente nesse momento é o inconformismo. Isso ficou evidente na fala de " $H$ " diante de um diagnóstico, cujo prognóstico dependeria de uma série de alterações no seu estilo de vida, que incluiu deixar seu trabalho de professora, a fim de ter a doença relativamente controlada. "C" mostra-se mais acomodada com a situação, já que declara que estava desempregada quando os sintomas surgiram.

Diferentemente das outras participantes que expressaram 
emoções negativas diante do diagnóstico da doença, a participante "A", cuja irmã falecida teve a mesma doença, se expressou sobre esta com muita naturalidade e sem nenhum rastro emocional. Possivelmente, para qualquer observador seria uma reação não condizente com a realidade da doença da irmã que terminara em óbito.

Evidencia-se, no processo da pesquisa, a variedade de formas de conviver com a doença dependendo da pessoa, da experiência de vida e até do grau de maturidade para perceber a dimensão e implicações da mesma (Radley, 1994). Portanto, destaca-se que em diferentes proporções e dependendo do momento, o LES tem causado algum tipo de impacto emocional nas participantes, provocando-lhes tristeza, choro, revolta, sofrimento, preocupação e medo. Em algumas ocasiões, esses sentimentos podem conduzir a um ciclo vicioso, em que tendem a desencadear novos sintomas e/ou agravar a situação, já que as doenças auto-imunes como o LES evidenciam a permanente interdependência das dimensões biológica e psicossocial (Moreira \& Mello Filho, 1992).

\section{Mudanças e limitações decorrentes do lúpus eritematoso sistêmico}

A doença crônica, na maioria dos casos, exige alterações no estilo de vida visando minimizar os sintomas e/ou mantê-la relativamente controlada (Radley, 1994; Remen, 1993). Neste estudo, as participantes destacam algumas das mudanças na sua vida: evitar exposição solar; não fazer esforço físico; não trabalhar; fazer dieta; tomar remédio sistematicamente e sofrer seus efeitos colaterais; conviver com o sofrimento da doença e preocupação pelos cuidados que ela demanda. Contudo, as reações a essas mudanças dependem muito do contexto econômico e social, do apoio que percebem e do tempo de convivência com a doença.

Assim, algumas das participantes citam as frustrações mais significativas decorrentes das limitações geradas pelo LES. "D", por exemplo, além das restrições mais comuns, lamenta por não poder morar em outro estado devido ao clima frio, o que lhe traria dores mais constantes nas articulações. Enquanto que "H" aproveita para evocar o quanto sofreu com o seu afastamento do trabalho. O mais significativo para "E" tem sido conviver com o sofrimento ante a possibilidade de morrer, deixando totalmente desamparado o filho de 8 anos, já que o pai da criança é ausente, tanto afetiva quanto financeiramente. Ela deixa em evidência os sintomas do abalo anímico, a ponto de falar para o filho que vai morrer apesar da doença não ter atingido órgãos vitais.

Algumas das participantes trouxeram a idéia da doença como "anormalidade" que as limita nas atividades cotidianas, incluindo as tarefas domésticas. Assim, as participantes "B" e "C" afirmaram que deixaram de ter uma vida "normal", esta última se lamentando também pela necessidade "de ter que depender do medicamento para toda a vida".

Os discursos de "A" e "F", embora não falem em "anormalidade", coincidem ao afirmarem que as mudanças sofridas giraram, primordialmente, em torno da impossibilidade de se expor ao sol e das limitações na realização de esforço físico.
Observa-se que a manifestação de vários sintomas ao mesmo tempo implica em diversas limitações sócio-ocupacionais, que atingem a subjetividade e a própria auto-imagem. De forma geral, todo esse contexto oriundo da doença tem repercutido na vida destas pessoas de diferentes formas, incluindo a possibilidade de apontar também formas alternativas de ver a adversidade. Assim, a participante "G" tenta não focar nas "perdas", destacando sempre as alternativas para não abdicar totalmente do que gosta de fazer. O que se justifica plenamente pela idade e pelo fato de a doença estar inativa desde sua primeira crise, além de estar sempre priorizando que "qualquer sacrifício é preferível para manter a saúde".

\section{A doença e os projetos de vida}

Percebe-se que, sendo a doença crônica uma ruptura no curso da vida, a tendência da pessoa é passar por diferentes momentos de crise que a fazem refletir sobre toda a vida passada, rever todos os seus valores e definir prioridades em função das suas atuais limitações e possibilidades (Grandesso, 2000; Remen, 1993).

Assim, quando questionadas sobre o seu sentimento em ser portadora de LES, e a forma como significam e lidam com a doença, nos deparamos com uma variedade de discursos que permitem compreender melhor a diversidade das experiências.

Embora a participante "A" conheça a doença, não só em relação a si mesma, mas também a partir da convivência com a sua irmã, ela não apenas teve dificuldade em compreender a pergunta, mas, ao respondê-la, expressou nunca ter pensado sobre isso. Além disso, ao longo da entrevista agiu como se a doença não fosse uma questão grave para ela. Essa atitude talvez decorra do fato de que a maioria dos membros da família sofre de diferentes doenças crônicas.

A participante "B" referiu que não se sente bem em ser portadora de LES, lembrando ainda que não gosta de falar sobre o assunto. Foi relevante a forma como "B" significa a doença, referindo-se a ela como o visitante indesejado que "apareceu praticamente do nada". Contudo, afirmou que já se acostumou com a doença e toma regularmente a medicação. " $C$ " afirmou que apesar de conviver há 16 anos com LES, tendo de abdicar da praia e sofrer outras limitações para mantê-la sob um relativo controle, mesmo assim, considera-se uma pessoa normal. Apesar de manifestar alguns sintomas, o tempo de convivência com a doença a leva a aceitar melhor sua condição e tentar se manter ativa socialmente.

Em contrapartida, “D”, apesar de ser portadora há 13 anos, até hoje se mostra muito revoltada e inconformada. Igualmente no caso de "E" observa-se frustração e inconformismo. A idéia fixa em encontrar uma solução e até uma cura para a sua doença esteve constantemente presente no seu discurso. Revelou, ainda, uma preocupação permanente, falando da doença como terminal e que a obrigaria a abandonar seu filho, caso ela venha a falecer.

A participante "F" mostra ao longo da entrevista uma personalidade bem estruturada e decidida. Embora os sintomas sejam mais permanentes e limitantes, tenta manter a doença sob controle através dos medicamentos e não exagerando 
nas atividades. Contudo, há momentos em que se lamenta da dependência dos medicamentos e de não poder trabalhar. Porém, percebe a necessidade de se manter lutando para controlar a situação o quanto puder, seja através dos remédios ou fazendo crochê como uma atividade fisioterápica incentivada pela médica, mas que também se tornou uma forma de aumentar a renda familiar.

Para "G", o momento do diagnóstico foi aterrorizante. Porém, como a doença está inativa há 3 anos, além de se sentir apoiada pela família e pelo namorado e manter suas atividades sociais e ocupacionais, ela se sente, conforme suas palavras, como "uma pessoa normal".

A participante "H" reconhece a sua preocupação com a sua condição de ser portadora de LES, porque a qualquer momento, pode ser surpreendida com a manifestação de um novo sintoma. No entanto, isso não a impediu de buscar alternativas que promovessem o seu crescimento e realização pessoal, mantendo-se ativa com as diversas ocupações criadas após a doença e a conseqüente aposentadoria forçada. Contudo, apesar dessa postura positiva frente à doença, assume suas limitações e fragilidade diante da possibilidade de enfrentar uma outra pessoa portadora de LES, não ocultando o impacto emocional que sente quando sabe que alguém manifesta a mesma doença.

Percebe-se que, apesar de toda a complexidade da doença e suas implicações psicossociais, a maioria das participantes ("A", "B", "C", "F", "G" e "H") revelou no seu discurso que aceita a doença e busca, em maior ou menor grau, alternativas para manter sua vida social mesmo diante das restrições impostas pela doença (Radley, 1994). Por seu turno, "D" e "E" mostram-se inconformadas e com muitas dificuldades para aceitá-la.

Em relação às perspectivas das participantes acerca do futuro, seus discursos podem ser agrupados em duas "categorias": (1) exclusivamente voltada para a doença; e (2) preocupação pela doença associada a outras conquistas como constituir uma família, estudar, trabalhar, reformar a casa e adquirir bens. Essas aspirações se resumem para algumas na preocupação de "manter uma vida normal".

A categoria centrada na doença foi ressaltada pelas participantes "D" e "E", lembrando que as duas apresentavam sintomas de depressão e mostraram um discurso reiterativo centrado nos problemas e com um viés marcado pela resignação cristã.

Enquanto que as participantes " $\mathrm{F}$ " e "H" destacaram tanto manter a doença controlada, como ter conforto e segurança através de possessão de bens, as participantes "A" e "G", até pela juventude, enfatizam também a realização de constituir uma família, estudar, ter uma profissão, trabalhar e passear. "B", além de fazer vestibular e se formar, tem como maior aspiração "viver uma vida normal", ao passo que para "C" ter sua vida "quase" normal foi o único desejo expressado.

Dessa forma, toda a história pessoal e os contextos dos quais participam (nos papéis de esposa, mãe, filha ou irmã; no trabalho ou na escola onde desempenham suas atividades; no hospital enquanto portadora de uma doença), as relações interpessoais estabelecidas por elas nos diversos contextos, incluindo também as distintas fontes de informação (televisão, rádio, jornal, entre outros) influenciam os processos de significação, evidenciando várias formas de dar sentido ao seu adoecer. Esses processos estarão permanentemente em movimento e promovendo mudanças conforme os novos contextos e papéis que elas venham a assumir ao longo de suas vidas, podendo, assim, sofrer modificações e gerar novos sentidos.

\section{Considerações finais}

Os livros e artigos científicos, em sua maioria, transmitem apenas o quadro clínico da doença, sem mencionar a pessoa portadora, enquanto que o diálogo com as participantes possibilitou uma maior compreensão acerca do que é ser portadora de LES. Assim, foi possível conhecer a visão de cada mulher enquanto pessoa que sofre, chora, tem frustrações e perdas advindas desse adoecer.

O sentido atribuído pela maioria das participantes sobre o LES é que ele é algo ruim, horrível, que apareceu do nada e que a qualquer hora pode se manifestar com novas exacerbações. No entanto, apesar dessa visão negativa e das mudanças impostas pela mesma, a maioria consegue estabelecer uma boa convivência com a doença, aceitando-a e tentando criar alternativas para preservar sua identidade social, sem, contudo, negligenciar os cuidados necessários para mantê-la relativamente sob controle.

Igualmente observa-se que, apesar das mudanças advindas do adoecer, algumas participantes não se detiveram nas perdas, preferindo focalizar a atenção no potencial que permanece. Assim, uma delas criou alternativas de trabalho com maior flexibilidade nos horários e a outra buscou estratégias que preservassem alguns programas de lazer, considerando o melhor horário para realizá-los. Contudo, as duas pessoas que se mostram emocionalmente mais afetadas pela doença continuam insistindo na possibilidade da cura, o que provavelmente as impede de vislumbrar outras possibilidades.

A convivência com a doença não impede que as participantes mais jovens criem expectativas quanto ao seu futuro, seja com o desejo de constituir uma família ou com a realização de uma carreira profissional. Enquanto que aquelas que já passaram por essa fase da vida esperam poder manter a doença sob controle para acabar de criar seus filhos e vê-los formados.

Observa-se que a doença repercute na vida das pessoas, especialmente quando forçadas a se afastar das atividades profissionais e/ou ocupacionais. Esse afastamento do trabalho repercute diretamente na situação econômica, em um contexto de limitações, afetando a única garantia de sobrevivência e sendo uma fonte de estresse e preocupação adicional para algumas participantes. Dessa forma, a aposentadoria fornecida pelo Instituto Nacional de Serviço Social (INSS) constitui um apoio relevante, que deveria ser adquirido sem tanta burocracia.

As narrativas das participantes revelam que os variados sintomas físicos e suas conseqüências são os que causam mais sofrimento. No entanto, após o estabelecimento da doença, os aspectos psicossociais passaram a ser tão importantes quanto os biológicos no tratamento dos sintomas e no relativo controle da doença. Assim, constata-se a necessidade de uma abordagem interdisciplinar que contemple a permanente interdependência 
entre as dimensões biológica, psicológica e social, visto que a sintomatologia produz múltiplas implicações que precisam ser consideradas.

Acredita-se, ainda, que o acompanhamento psicoterápico e/ou disponibilidade de grupos de apoio para portadores dessa doença seria relevante, pois permitiria a troca de suas experiências ao compartilharem suas angústias, temores e estratégias para ultrapassar as dificuldades impostas pela doença.

\section{Referências}

Bruner, J. (1997). Actos do significado - para uma psicologia cultural. Lisboa: Edições 70 .

Campos, F. C. B. (1992). A saúde mental e o processo saúde-doença: a subjetividade na afirmação/negação da cura. In F. C. B. Campos (Org.), Psicologia e saúde: repensando práticas (pp. 41-46). São Paulo: Hucitec.

Chartash, E. (2001). Cardiopulmonary disease and lupus. Acessado em 10 de abril de 2001 do World Wide Web: http://www.hamline.edu/lupus/index.html.

Dobkin, P. L., Da Costa, D., Fortin, P. R., Edworthy, S., Barr, S., Esdaile, J. M., Senécal, J. L., Goulet, J. R., Choquette D., Rich, E., Beaulieu, A., Cividino, A., Ensworth, S., Smith, D., Zummer, M., Gladman, D., \& Clarke, A. E. (2001). Living with lupus: a prospective Pan-Canadian study. The Journal of Rheumatology, 28(11), 2442-2448.

Edelmann, R. J. (2000). Chronic illness. In Psychosocial aspects of the health care process (pp. 169-186). Londres: Prentice Hall.

Grandesso, M. A. (2000). Sobre a reconstrução do significado: uma análise antropológica e hermenêtica da prática clínica. São Paulo: Casa do Psicólogo.

Hanly, J. G. (1991). Systemic lupus erythematosus and the nervous system. Acessado em 10 de março de 2002 do World Wide Web: http://www. lupuscanada.org.

Krauthamer, A., Coelho, L. E., \& Sato, E. I. (1999). Tratamento do LES. In E. I. Sato (Org.), Lúpus Eritematoso Sistêmico - O que é? Quais são suas causas? Como se trata? (pp. 26-31). São Paulo: Sociedade Brasileira de Reumatologia.
Lockshin, M. D. (2001). Pregnancy and lupus. Acessado em 10 de abril de 2001 do World Wide Web: http://www.hamline.edu/lupus/index.html.

Meinão, I. M., Assis, L. S. S., \& Sato, E. I. (1999). Manifestações clínicas no lúpus eritematoso sistêmico. In E. I. Sato (Org.), Lúpus Eritematoso Sistêmico - O que é? Quais são suas causas? Como se trata? (pp. 9-15). São Paulo: Sociedade Brasileira de Reumatologia.

Moreira, M. D., \& Mello Filho, J. (1992). Psicoimunologia hoje. In J. Mello Filho (Org.), Psicossomática hoje (pp. 119-151). Porto Alegre: Artes Médicas.

Murray, M. (1999). The storied nature of health and illness. In M. Murray \& K Chamberlain (Orgs.), Qualitative health psychology: theories \& methods (pp. 47-63). Londres: Sage.

Radley, A. (1994). Making sense of illness. The social psychology of health and disease. Londres: Sage.

Radley, A. (1999). Social realms and the qualities of illness experience. In M Murray \& K. Chamberlain (Org.), Qualitative health psychology: theories \& methods (pp. 16-29). Londres: Sage.

Remen, N. (1993). O paciente como ser humano. São Paulo: Summus.

Sato, E. I. (1999). Introdução. In E. I. Sato (Org.), Lúpus Eritematoso Sistêmico - O que é? Quais são suas causas? Como se trata? (pp. 5-8). São Paulo: Sociedade Brasileira de Reumatologia.

Sato, E. I., Bonfá, E. D., Costallat, L. T. L., Silva, N. A., Brenol, J. C. T., Santiago, M. B., Szajubok, J. C. M., Filho, A. R., Barros, R. T., \& Vasconcelos, M. (2002). Consenso brasileiro para o tratamento do lúpus eritematoso sistêmico (LES). Revista Brasileira de Reumatologia, 42(6), 362-370.

Shapiro, H. S. (2001). Depression in lupus. Acessado em 10 de abril de 2001 do World Wide Web: http://www.hamline.edu/lupus/index.html.

Spink, M. J. P., \& Gimenes, M. G. G. (1994). Práticas discursivas e produção de sentido: apontamentos metodológicos para a análise de discursos sobre a saúde e a doença. Saúde e Sociedade, 3(2), 149-171.

Stevens, M. B. (2001). Joint and muscle pain in lupus. Acessado em 10 de abril de 2001 do World Wide Web: http://www.hamline.edu/lupus/index.html.

Villar, M. J. P., \& Sato, E. I. (2001). Estimando a incidência de lúpus eritematoso sistêmico em Natal/RN-Brasil. Comunicação apresentada na XVI Jornada Brasileira de Reumatologia e XIII Jornada do Cone-Sul de Reumatologia, Florianópolis, Santa Catarina.

Zerbini, C. A., \& Fidelix, T. S. A. (1989). Conversando sobre lúpus: um livro para o paciente e sua família. São Paulo: Roca.

${ }^{1}$ Pesquisou-se na Sociedade Brasileira de Reumatologia e no site do Ministério da Saúde e não foram encontrados, até o momento, dados epidemiológicos no Brasil. O que vem a confirmar a informação de Sato (1999).

${ }_{2}^{2}$ Salário mínimo correspondente ao ano de 2003.

Adriana Dias Araújo, mestre em Psicologia pela UFRN, é psicóloga no Centro de Referência da Assistência Social-CRAS do município de Natal. Endereço para correspondência: Rua Aeroporto de Cumbica, 22 (Emaús); Parnamirim, RN; CEP: 59150-000. Tel.: (84) 3643-4573. E-mail: adriaraujo_dias@yahoo.com. br

Martha Azucena Traverso-Yépez, doutora em Psicologia Social pela Universidade Complutense de Madri, é professora no Departamento de Psicologia da Universidade Federal do Rio Grande do Norte. E-mail: traverso@ufrnet.br 